\title{
Quitting Smoking May Restore Hematological Characteristics within Five Years
}

\author{
ELFRIEKE D. VAN TIEL, MSc, PETRA H.M. PEETERS, MD, PhD, HENRIETTE A. SMIT, PHD, NICO \\ J.D. NAGELKERKE, MD, PhD, A. JEANNE M. VAN LOON, PhD, DIEDERIK E. GROBBEE, MD, PhD, \\ AND H. BAS BUENO-DE-MESQUITA, MD, MPH, PHD
}

\begin{abstract}
PURPOSE: To describe the cross-sectional association of counts of total and subtypes of leukocytes, platelets, and selected characteristics of red blood cells with intensity of cigarette smoking and smoking cessation.

METHODS: The study population consisted of 16,254 men and women 20-70 years of age who participated in the Dutch European Prospective Investigation into Cancer and nutrition (EPIC) subcohort, 1995-1997. Linear regression analysis was performed, for both sexes separately, to study the relation between various measurements of smoking habits and hematologic characteristics.

RESULTS: Among current smokers, in both genders, packyears and daily number of cigarettes were associated with increased leukocytes (6-19\%), lymphocytes (4-14\%), monocytes (3-9\%), neutrophils (7$24 \%)$, platelets $(1-5 \%)$, mean corpuscular volume $(0.4-2 \%)$, hematocrit $(0.3-4 \%)$, hemoglobin $(0.3-$ $4 \%)$, and mean corpuscular hemoglobin $(0.8-2 \%)$. In subjects who had quitted smoking within two years before blood measurement, hematological characteristics in most cells were similar as in never smokers, whereas normal counts of lymphocytes and monocytes were observed only 2-5 years after quitting.

CONCLUSIONS: Our findings suggest a marked influence of current smoking habits on leukocyte counts and, to a lesser extent, on counts of erythrocytes and platelets. Following smoking cessation, at least five years have to pass before changes in all hematological parameters may return to normal values. Ann Epidemiol 2002;12:378-388. ㄷ 2002 Elsevier Science Inc. All rights reserved.
\end{abstract}

KEY WORDS: Cigarette Smoking, Leukocytes, Lymphocytes, Monocytes, Neutrophils, Eosinophils, Thrombocytes, Red Blood Cells, Heamatocrit, Haemoglobin.

\section{INTRODUCTION}

Total and subtypes of white blood cell counts have been associated with cardiovascular disease, respiratory function and symptoms, and cancer (1-8). Several mechanisms underlying these associations have been proposed $(1-3,7,9)$. It is unclear, however, whether this is a direct effect or just a reflection of other underlying risk factors.

The strongest known correlate of the leukocyte count is cigarette smoking, with smokers having higher mean counts than never smokers $(1-6,10-15)$. Some studies reported an increase in leukocyte count with number of cigarettes

From the Department of Chronic Diseases Epidemiology (E.D.V.T., H.A.S., A.J.M.V.L., H.B.B.D.M.) and Computerization and Methodological Consultancy (N.J.D.N.), National Institute of Public Health and Environment, Bilthoven, The Netherlands; and Julius Center for Patient Oriented Research, Academic Hospital Utrecht, Utrecht, The Netherlands (P.H.M.P., D.E.G.).

Address reprint requests to: $\mathrm{H}$. Bas Bueno-de-Mesquita, MD, MPH, $\mathrm{PhD}$, Department of Chronic Diseases Epidemiology, National Institute of Public Health and Environment, P.O. Box 1, 3720 BA BILTHOVEN, The Netherlands.

Received August 27, 2000; revised July 24, 2001; accepted August 17 2001 smoked daily and a decrease after cessation of smoking (9$11,13,14)$. Unlike total leukocyte count, the associations between leukocyte subpopulations and smoking habits, including the effect of quitting, have not been explored extensively. The studies, mostly conducted in men, which did, reported positive associations between smoking and counts of the leukocyte subpopulations, neutrophils, eosinophils, monocytes, and lymphocytes $(2,9,10,16)$.

Cigarette smoking is also reported to be related to the red blood cell population and thrombocytes. Helman and coworkers reported a lower erythrocyte count in male smokers than in never smokers, while no relation was found in women (17). In both genders, in comparison to never smokers, smokers have higher values of mean corpuscular volume, hematocrit, hemoglobin, mean corpuscular hemoglobin, and platelet count $(11,17-21)$. Green and coworkers, however, showed a lower platelet count in female smokers than in never smokers (19).

The purpose of this cross-sectional study is to further explore and quantify the association of total counts and subpopulations of leukocytes, counts of platelets, and selected characteristics of red blood cells to various measures of intensity of cigarette smoking and smoking cessation in men 
Selected Abbreviations and Acronyms

$\mathrm{EPIC}=$ European investigation into cancer and nutrition

$\mathrm{MCH}=$ mean corpuscular hemoglobin

$\mathrm{MCV}=$ mean corpuscular volume

and women. The study was conducted in 16,254 subjects, 20 to 70 years of age, who participated in the Dutch EPIC cohort (European Prospective Investigation into Cancer and nutrition), 1995-1997.

\section{MATERIALS AND METHODS}

\section{Study Population}

The population of the present study was derived from the MORGEN-EPIC and the PROSPECT-EPIC studies, conducted from 1993 up to 1997, which represent the Dutch part of the EPIC study, a large international cohort study investigating the relation of lifestyle factors with the development of chronic diseases (22).

The population sample of the MORGEN-EPIC study consisted of men and women 20-65 years of age residing in three Dutch towns, Maastricht, Amsterdam, and Doetinchem. During the study period, in Amsterdam and Maastricht each year new age- and sex-stratified random samples were drawn. In Doetinchem, subjects, who first had been examined in the previous monitoring project during 19871992, were re-examined in 1993-1997, whereas for monitoring purposes small samples of subjects 20-25 years of age were added each year.

The PROSPECT-EPIC cohort consisted of women, 49 to 70 years of age, recruited from among participants of the national breast cancer screening program in Utrecht. Participants of both studies received two questionnaires to complete at home, viz. a general and a dietary questionnaire, and were invited to attend a medical examination at the Municipal Health Service of each town and at the breast cancer-screening center, respectively. The mean response rate of the MORGEN-EPIC study in 1995, 1996, and 1997 was 43\%, whereas the PROSPECT-EPIC study had a mean response rate in 1995 and 1996 of 38\%. In 1993, the MORGEN-EPIC and PROSPECT-EPIC studies were approved by the medical ethical committees of TNO and of the Academic Hospital Utrecht, respectively.

\section{Blood Collection and Assay}

Since June 1995, with the exception of the participants of the mobile breast cancer screening program, at the medical examination at entry into the cohort, a blood sample was drawn of all subjects in an EDTA monovette for measurement of the complete differential five-population cell count, and the red blood cell and platelet counts.
In the MORGEN-EPIC study, in the peripheral study centers, the samples were kept at room temperature for thirty minutes to three hours, allowing slight swelling of cells and stabilization of size, after which they were stored at $+5{ }^{\circ} \mathrm{C}$ and transported overnight in a coolbox to the central Cryolaboratory of RIVM.

In the PROSPECT-EPIC study, the samples were stored at room temperature until the arrival at the central Cryolaboratory at the end of the day. During the night, the samples were stored at $+5^{\circ} \mathrm{C}$. The next day the samples of both studies were again kept at room temperature for at least thirty minutes and measured in a Coulter counter MAXM.

The short-term stability of the hematologic characteristics during the interval between collection until measurement next day has been tested (Vijfvinkel KI, Stability of blood parameters, 1996). It was concluded that an interval up to 24 hours had only little influence (Spearman correlation: 0.84-0.99) on all parameters, with the exception of basophils, and mean corpuscular haemoglobin concentration.

During January 1996 up to December 1997, we participated in the Interlaboratory Quality Assurance Program by Coulter Corporation, Miami, Florida. According to this program, only our mean platelet volume measurements were not reliable. Consequently, total white and red blood cell count, percentages of subpopulations of white blood cells (except basophils), mean corpuscular volume, hemoglobin, and platelet count, which were all directly measured, were available for analysis. The computed hematologic characteristics, which were available, were absolute counts of lymphocytes, monocytes, neutrophils, and eosinophils and hematocrit, and mean corpuscular hemoglobin.

\section{Questionnaires}

At entry into the cohort smoking history was assessed by a general questionnaire. First, subjects were asked whether they smoked cigarettes at the time of study entry. If so, they were asked how many cigarettes per day they currently smoke and whether they usually smoke filter or non-filter cigarettes. Former smokers were asked for the age at quitting. Among ever smokers, information was elicited on age at start of smoking, whether they had stopped for a while, and if so, how many years they had stopped and the amount of cigarettes per day in the past.

The MORGEN questionnaire contains a single question on the usual number of cigarettes smoked in the past, whereas the PROSPECT questionnaire assessed past intensity of smoking by asking how many cigarettes were smoked at ages 20, 30, 40, and 50 years. Therefore, in the latter study, the usual daily number of cigarettes smoked in the past was estimated by the daily number of cigarettes at the particular age multiplied by the years smoked in the following ten years. In both studies, packyears, representing life- 
time consumption, was defined to be the product of years of smoking with the mean of the daily number of cigarettes smoked currently and in the past, divided by 20 (the average number in a packet of cigarettes). During the medical examination, the subjects were asked whether they had smoked cigarettes during 24 hours prior to drawing the blood sample (yes; no).

Alcohol intake (g/day) was assessed by the dietary questionnaire, which included questions on the usual drinking of different types of alcoholic beverages (23). Body mass index was defined as weight/body height ${ }^{2}\left(\mathrm{~kg} / \mathrm{m}^{2}\right)$ and diastolic blood pressure $(\mathrm{mmHg})$ as the mean of two measurements. Women, who did not menstruate the preceding 12 months and were not pregnant, were classified as post-menopausal. Selfreported surgical removal of the uterus or both ovaries was treated as missing regarding menopausal status.

From June 1995 up to December 1997, at baseline 20,797 subjects were examined in both cohorts. During this period, blood cell counts were not available either because the blood was not collected for women examined in mobile screening program $(n=4375)$ or the blood was collected but the sample was too small or the blood had clotted $(n=$ 10). Two subjects were excluded because their blood samples were considered to be abnormal by the lab technician. Valid smoking data were missing for 156 subjects. Therefore, the final study population amounts to 16,254 subjects, i.e., 4668 men and 5609 women from MORGEN-EPIC and 5977 women from PROSPECT.

\section{Data Analysis}

The SAS version 6.12 package was used for statistical analyses. In all analyses, $p$-values below 0.05 were considered to be statistically significant. Since true underlying increases in absolute cell counts of specific cell types (computed by multiplying directly measured proportions with the independently measured white blood cell count) may show up as apparent stable or even decreases in directly measured proportions, computed absolute counts were used in the analyses. Freedman and coworkers suggested to control for differential counts in the analyses, because of interrelationships between these counts (9). Clearly, however, correction for other subtypes would imply correction for smoking, and therefore, no such correction was performed in the regression analyses.

Linear regression analysis was performed, using procedure GLM, for both sexes separately, to study the cross-sectional relation between various measurements of smoking intensity and the hematologic characteristics measured only once at entry into the cohort. For comparability with published literature, the analysis was stratified by sex. The dependent variable in all regression analyses was the blood parameter of interest, and the independent variables included the smoking variables of interest and age. Age, as a continuous variable, was included in all models. In order to obtain comparable regression coefficients, the daily numbers of filter and non-filter cigarettes were both included as independent variables in the regression model. The distributions of most hematologic values were approximately log-normal; therefore, natural log-transformation was applied for all dependent variables. Consequently, regression coefficients indicate the change in percentage of the blood parameter of interest. Values for percentage differences were obtained by exponentiating and multiplication by 100 of regression coefficients.

Sex, age, alcohol intake, body mass index, and diastolic blood pressure tend to be correlates of smoking habits (20, 24) and could potentially be correlates of peripheral blood counts $(10,13-14,20,25,26)$. Menopausal status has been related to a lower leukocyte and neutrophil count and a higher MCV and could potentially be related to smoking habits $(27,28)$. The potential confounding effect of drinking alcohol, body mass index, mean diastolic blood pressure, and menopausal status was assessed simultaneously by comparing the regression coefficients of the smoking variables of models with and without these potential confounders. As these potential confounders did not essentially change these regression coefficients, they were not included in the final regression models.

Therefore, all regression models included the log-transformed blood parameter of interest as dependent variable, and smoking variables of interest and age as explanatory variables. Because some data on smoking were missing, the exact number of subjects on which the linear regression analyses were based may differ (maximum missing: 6.7\%).

\section{RESULTS}

The sample of 16,254 subjects in our analyses included 4668 men and 11,586 women. Among men, mean age was 42.7 years $(\mathrm{SD}=11.0)$ (Table 1$)$. Male smokers, who did not smoke 24 hours prior to drawing the blood sample $(9.6 \%)$, had a relatively low mean current dose of $3.4(\mathrm{SD}=$ 7.2) cigarettes per day. Among women, mean age was 49.1 years $(\mathrm{SD}=11.5)$. The mean current dose of the female smokers, who did not smoke 24 hours prior to drawing the blood specimen $(9.8 \%)$, was low too and amounted to 2.5 $(\mathrm{SD}=4.8)$ cigarettes per day. For both genders, geometric means of all hematologic values were higher among current smokers than among never smokers and former smokers, except for the red blood cell count, which was slightly lower in smokers (Tables 2 and 3).

In both sexes, counts of leukocytes, leukocyte subpopulations, and platelets were higher among current smokers than among those who never smoked with the largest proportional increase for eosinophils $( \pm 50 \%)$ (Table 4). Eosinophils, however, were not related to smoking intensity. 
TABLE 1. Selected characteristics of the study population, Dutch EPIC cohort, 1995-1997

\begin{tabular}{|c|c|c|}
\hline & $\begin{array}{c}\text { Men } \\
(n=4,668) \\
\text { Mean }(\mathrm{SD}) \text { or } \%\end{array}$ & $\begin{array}{c}\text { Women } \\
(n=11,586) \\
\text { Mean }(\mathrm{SD}) \text { or } \%\end{array}$ \\
\hline Age & $42.7(11.0)$ & $49.1(11.5)$ \\
\hline Alcohol intake $(\mathrm{g} / \text { day })^{\mathrm{a}}$ & $17.9(21.0)$ & $9.1(12.5)$ \\
\hline $\begin{array}{l}\text { Mean diastolic blood pressure } \\
(\mathrm{mmHg})^{\mathrm{a}}\end{array}$ & $79.3(10.6)$ & $76.8(10.7)$ \\
\hline \multicolumn{3}{|l|}{ Smoking status ${ }^{\mathrm{a}}$} \\
\hline $\begin{array}{l}\text { Never smokers } \\
\text { Former smokers } \\
\text { Current smokers }\end{array}$ & $\begin{array}{l}30.7 \\
33.2 \\
36.1\end{array}$ & $\begin{array}{l}40.3 \\
31.0 \\
28.7\end{array}$ \\
\hline \multicolumn{3}{|l|}{ Within current smokers } \\
\hline $\begin{array}{l}\text { Cigarettes/day } \\
\text { Packyear }^{\mathrm{a}} \\
\text { Filter use }^{\mathrm{a}} \\
\text { Not smoked last } 24 \text { hours }^{\mathrm{a}}\end{array}$ & $\begin{array}{l}14.9(9.9) \\
18.7(15.6) \\
45.4 \\
9.6\end{array}$ & $\begin{array}{l}13.2(8.8) \\
16.8(12.4) \\
74.9 \\
9.8\end{array}$ \\
\hline \multicolumn{3}{|l|}{ Within former smokers } \\
\hline Years since quitting $^{\mathrm{a}}$ & $13.0(9.1)$ & $14.9(10.0)$ \\
\hline
\end{tabular}

An increase with usual daily number of cigarettes was seen for lymphocytes, monocytes, neutrophils, and platelets, with the largest increase for neutrophils (21-25\% per 20 cigarettes/day). No difference was seen between the effect of daily number of filter and non-filter cigarettes on the white blood cells and platelets (data not shown). With the exception of eosinophil count, among current smokers all counts increased with lifetime number of cigarettes smoked, but these increases were lower than $10 \%$ per packyear.

In contrast to elevated levels seen in current smokers, former smokers, even those who had quit in the previous year, clearly had smaller positive differences with never smokers in leukocyte subtypes and platelets (Figure 1). For reasons of scale, findings on eosinophils were not graphed. The neutrophil count showed no difference between former smokers and never smokers already one year after quitting. Values of lymphocyte and monocyte counts equal to those in never smokers were seen only several years after quitting, e.g., only among those who had quit five years or longer the lymphocyte count was not anymore different from the count in never smokers. Not only a long-term effect of quitting was seen. Compared to smokers who did smoke within 24 hours of the measurement, even not smoking in the 24 hours prior to drawing the blood sample was associated with lower levels in neutrophils of 7-15\%, in lymphocytes of $6-9 \%$, whereas a lower count of monocytes was seen in women only (Table 4).

Overall, relations of smoking habits with characteristics of red blood cells were considerably weaker than with white blood cells. In both genders, mean corpuscular volume $(\mathrm{MCV})$ and mean corpuscular hemoglobin $(\mathrm{MCH})$ were higher in current smokers than in never smokers $(2-4 \%)$, whereas the red blood cell count was lower in current smokers (1-2\%) (Table 5). In men and women, higher levels of MCV, hematocrit, hemoglobin, and $\mathrm{MCH}$ were shown with increasing daily number of cigarettes $(1-4 \%$ per 20 cigarettes). Despite the depressed levels of erythrocyte counts in current smokers in both genders, only in women, a small unexpected increase in erythrocyte count was seen the more cigarettes were smoked each day. No difference was seen in the effect of daily number of filter and non-filter cigarettes on the red blood cells (data not shown). A small increase of MCV, hematocrit, and hemoglobin was shown with lifetime number of cigarettes smoked.

In both genders, the longer ago subjects had quit the smaller the difference in red blood cell counts with never smokers (Figure 2). In men, two years after quitting no difference in red blood cell count, $\mathrm{MCV}$, and $\mathrm{MCH}$ could be seen anymore between former and never smokers; in women, the difference between former and never smokers seems to continue longer than five years after quitting. In women only, where current smokers had higher hematocrit and hemoglobin values than never smokers, already among those who stopped smoking within the previous year, hematocrit and hemoglobin values were the same as in never smokers. Compared to male smokers who did smoke within the prior 24 hours, in men not smoking for 24 hours prior to measurement lower counts of $\mathrm{MCV}$ and $\mathrm{MCH}$ were seen (Table 5).

\section{DISCUSSION}

The results of this large-scale study demonstrate that, in both genders, cigarette smoking is positively associated with total leukocyte and differential counts, and to a lesser extent, platelets, and characteristics of the red blood cell population. In contrast, smoking is inversely associated with the number of red blood cells. These results are consistent with previous studies $(2,9-11,16-21,29)$. Importantly, we found that in those who had quit within the last two years most hematological characteristics were similar to levels in never smokers, however, for lymphocytes and monocytes this was the case five years after quitting only. Finally, compared to those who continued to smoke, several hematological characteristics in subjects not smoking within the 24 hours preceding the measurement were considerably closer to levels in never smokers.

Certain limitations of our analysis need to be pointed out. First, since in our cross-sectional analyses relations can only be examined between questionnaire and laboratory measures in different individuals made at one point in time, despite the fact that an effect of hematological characteristics on smoking habits is not biologically plausible, a possible temporal relationship between changes in smoking 
TABLE 2. Men: geometric mean $\left(e^{2} d^{a}\right)$ values of the hematologic characteristics by smoking status, Dutch EPIC cohort, 1995-1997

\begin{tabular}{|c|c|c|c|c|c|}
\hline \multirow[b]{3}{*}{$\operatorname{Men}(n=4665)$} & \multicolumn{5}{|c|}{ Smoking status } \\
\hline & \multirow[b]{2}{*}{$\begin{array}{l}\text { Never smokers } \\
\quad(n=1434)\end{array}$} & \multirow[b]{2}{*}{$\begin{array}{l}\text { Former smokers } \\
\quad(n=1547)\end{array}$} & \multicolumn{3}{|c|}{ Current smokers ${ }^{\mathrm{b}}$} \\
\hline & & & $\begin{array}{l}1^{\text {st }} \text { tertile } \\
(n=559)\end{array}$ & $\begin{array}{l}2^{\text {nd }} \text { tertile } \\
(n=557)\end{array}$ & $\begin{array}{l}3^{\text {rd }} \text { tertile } \\
(n=568)\end{array}$ \\
\hline WBC count $\left(10^{9} / \mathrm{L}\right)$ & $5.8(1.3)$ & $6.1(1.3)$ & $6.5(1.3)$ & $7.4(2.1)$ & $8.2(1.3)$ \\
\hline Lymphocyte $\left(10^{9} / \mathrm{L}\right)$ & $1.7(1.3)$ & $1.8(1.4)$ & $2.0(1.3)$ & $2.2(1.4)$ & $2.3(1.4)$ \\
\hline Monocyte $\left(10^{9} / \mathrm{L}\right)$ & $0.5(1.8)$ & $0.5(1.6)$ & $0.5(1.4)$ & $0.6(2.0)$ & $0.6(2.4)$ \\
\hline Neutrophil $\left(10^{9} / \mathrm{L}\right)$ & $3.3(1.4)$ & $3.4(1.4)$ & $3.6(1.4)$ & $4.5(1.4)$ & $4.8(1.5)$ \\
\hline Eosinophil $\left(10^{9} / \mathrm{L}\right)$ & $0.1(12.7)$ & $0.1(8.9)$ & $0.2(5.6)$ & $0.2(6.4)$ & $0.2(5.2)$ \\
\hline Platelet count $\left(10^{9} / \mathrm{L}\right)$ & $225.2(1.3)$ & $230.5(1.2)$ & $227.3(1.3)$ & $235.2(1.3)$ & $239.9(1.3)$ \\
\hline RBC count $\left(10^{12} / \mathrm{L}\right)$ & $5.1(1.1)$ & $5.0(1.1)$ & $5.0(1.1)$ & $4.9(1.1)$ & $5.0(1.1)$ \\
\hline $\operatorname{MCV}(f l)$ & $90.0(1.0)$ & $90.8(1.0)$ & $91.3(1.0)$ & $92.7(1.0)$ & $92.8(1.0)$ \\
\hline Hematocrit (L/L) & $0.46(1.07)$ & $0.46(1.06)$ & $0.46(1.06)$ & $0.46(1.07)$ & $0.46(1.06)$ \\
\hline Hemoglobin $(\mathrm{mmol} / \mathrm{L})$ & $9.6(1.1)$ & $9.5(1.1)$ & $9.5(1.1)$ & $9.6(1.1)$ & $9.6(1.1)$ \\
\hline $\mathrm{MCH}(\mathrm{fmol})$ & $1.9(1.0)$ & $1.9(1.1)$ & $1.9(1.1)$ & $1.9(1.1)$ & $1.9(1.1)$ \\
\hline
\end{tabular}

Missing: 3.

aesd, exponent $\left(\mathrm{sd}_{\mathrm{ln}}\right)$; approximate $25 \%$ and $75 \%$ percentiles can be computed by dividing and multiplying the geometric mean by esd ${ }^{0.675}$.

${ }^{\mathrm{b}}$ Cut off: $\leqslant 10$ cigarettes per day and $\geqslant 19$ cigarettes per day.

habits on changes in hematologic characteristics can only be assumed but not definitely proven. Next, selective inclusion, or exclusion of subjects with specific hematological characteristics due to the moderate mean response rates in both substudies, i.e., 38 and $43 \%$, cannot be excluded. However, it is difficult to envisage how selection bias could have influenced the observed associations between smoking and hematological characteristics.

A non-response study comparing nonrespondents and respondents of the MORGEN-study indicated a selective loss at baseline of currently smoking subjects and nonconsumers of alcohol. Yet, in a further follow-up study of the MORGEN respondents, associations between smoking status and socioeconomic status or perceived health were not different between respondents and nonrespondents (van Loon et al., submitted for publication). Further, characteristics of platelets and white and red blood cells were measured approximately 24 hours after drawing blood. Although this may have introduced measurement error, the relatively high correlation coefficients, obtained in the stability study, indicate that even after 24 hours ranking is largely preserved. Finally, adjustment for a variety of potential confounders did not materially change our findings. Yet, residual confounding can not be excluded as for example in the inconsistency found in the effect

TABLE 3. Women: geometric mean $\left(\mathrm{esd}^{\mathrm{a}}\right)$ values of the hematologic characteristics by smoking status, Dutch EPIC cohort, 1995-1997

\begin{tabular}{|c|c|c|c|c|c|}
\hline \multirow[b]{3}{*}{ Women $(n=11,578)$} & \multicolumn{5}{|c|}{ Smoking status } \\
\hline & \multirow[b]{2}{*}{$\begin{array}{l}\text { Never smokers } \\
\quad(n=4671)\end{array}$} & \multirow[b]{2}{*}{$\begin{array}{l}\text { Former smokers } \\
\quad(n=3586)\end{array}$} & \multicolumn{3}{|c|}{ Current smokers ${ }^{\mathrm{b}}$} \\
\hline & & & $\begin{array}{l}1^{\text {st }} \text { tertile } \\
(n=1168)\end{array}$ & $\begin{array}{l}2^{\text {nd }} \text { tertile } \\
(n=1127)\end{array}$ & $\begin{array}{l}3^{\text {rd }} \text { tertile } \\
(n=936)\end{array}$ \\
\hline WBC count $\left(10^{9} / \mathrm{L}\right)$ & $6.1(1.3)$ & $6.0(1.6)$ & $6.6(1.3)$ & $7.6(1.7)$ & $8.2(1.3)$ \\
\hline Lymphocyte $\left(10^{9} / \mathrm{L}\right)$ & $1.7(1.4)$ & $1.7(1.5)$ & $1.9(1.4)$ & $2.1(1.4)$ & $2.3(1.3)$ \\
\hline Monocyte $\left(10^{9} / \mathrm{L}\right)$ & $0.4(1.8)$ & $0.4(1.8)$ & $0.4(2.1)$ & $0.4(1.7)$ & $0.5(1.8)$ \\
\hline Neutrophil $\left(10^{9} / \mathrm{L}\right)$ & $3.6(1.5)$ & $3.6(1.4)$ & $3.9(1.4)$ & $4.7(1.4)$ & $5.0(1.5)$ \\
\hline Eosinophil $\left(10^{9} / \mathrm{L}\right)$ & $0.1(26.9)$ & $0.1(25.2)$ & $0.1(15.5)$ & $0.1(14.4)$ & $0.1(15.1)$ \\
\hline Platelet count $\left(10^{9} / \mathrm{L}\right)$ & $251.3(1.3)$ & $252.9(1.3)$ & $251.4(1.3)$ & $257.1(1.3)$ & $262.0(1.3)$ \\
\hline RBC count $\left(10^{12} / \mathrm{L}\right)$ & $4.5(1.1)$ & $4.4(1.1)$ & $4.4(1.1)$ & $4.4(1.1)$ & $4.5(1.1)$ \\
\hline $\operatorname{MCV}(\mathrm{fl})$ & $89.5(1.1)$ & $90.4(1.1)$ & $91.4(1.0)$ & $92.8(1.1)$ & $93.4(1.1)$ \\
\hline Hematocrit (L/L) & $0.40(1.08)$ & $0.40(1.08)$ & $0.40(1.09)$ & $0.41(1.09)$ & $0.42(1.08)$ \\
\hline Haemoglobin $(\mathrm{mmol} / \mathrm{L})$ & $8.3(1.1)$ & $8.3(1.1)$ & $8.4(1.1)$ & $8.6(1.1)$ & $8.7(1.1)$ \\
\hline $\mathrm{MCH}(\mathrm{fmol})$ & $1.9(1.1)$ & $1.9(1.1)$ & $1.9(1.1)$ & $1.9(1.1)$ & $2.0(1.1)$ \\
\hline
\end{tabular}

Missing: 8

${ }^{a}$ esd, exponent $\left(\mathrm{sd}_{\mathrm{ln}}\right)$; approximate $25 \%$ and $75 \%$ percentiles can be computed by dividing and multiplying the geometric mean by esd ${ }^{0.675}$.

${ }^{b}$ Cut off: $\leqslant 9$ cigarettes per day and $\geqslant 15$ cigarettes per day. 
TABLE 4. Percentage differences in hematological characteristics of white blood cells and platelets between various (ex)smoking categories and non-smoking (reference) by gender, Dutch EPIC cohort, 1995-1997

\begin{tabular}{|c|c|c|c|c|c|c|}
\hline & WBC & Lymphocyte & Monocyte & Neutrophil & Eosinophil & Platelet \\
\hline & $\beta^{\mathrm{a}}\left(\mathrm{SE}^{\mathrm{b}}\right)$ & $\beta^{\mathrm{a}}(\mathrm{SE})$ & $\beta^{\mathrm{a}}(\mathrm{SE})$ & $\beta^{\mathrm{a}}(\mathrm{SE})$ & $\beta^{\mathrm{a}}(\mathrm{SE})$ & $\beta^{\mathrm{a}}(\mathrm{SE})$ \\
\hline \multicolumn{7}{|l|}{ Men } \\
\hline \multicolumn{7}{|l|}{ Smoking status ${ }^{\mathrm{e}}$} \\
\hline Never smokers & Reference & & & & & \\
\hline \multicolumn{7}{|l|}{ Former smokers } \\
\hline$\leqslant 1$ year since quitting & $7.4^{\mathrm{d}}(2.7)$ & $12.9^{\mathrm{d}}(2.4)$ & $13.0^{\mathrm{d}}(4.7)$ & $2.9(2.7)$ & $17.8(17.3)$ & $1.6(1.9)$ \\
\hline $1-2$ years since quitting & $5.0(4.1)$ & $11.4^{\mathrm{d}}(3.6)$ & $6.4(7.1)$ & $1.5(4.1)$ & $3.6(26.1)$ & $7.4^{\mathrm{d}}(2.8)$ \\
\hline $2-5$ years since quitting & $6.0^{\mathrm{d}}(2.7)$ & $9.7^{\mathrm{d}}(2.4)$ & $9.8^{\mathrm{d}}(4.7)$ & $4.1(2.7)$ & $42.5^{\mathrm{d}}(17.2)$ & $3.6^{\mathrm{d}}(1.9)$ \\
\hline$>5$ years since quitting & $-0.6(1.4)$ & $0.5(1.3)$ & $2.3(2.5)$ & $-1.3(1.4)$ & $16.1(9.1)$ & $1.4(1.0)$ \\
\hline Current smokers & $23.1^{\mathrm{d}}(1.2)$ & $21.4^{\mathrm{d}}(1.1)$ & $17.9^{\mathrm{d}}(2.1)$ & $25.6^{\mathrm{d}}(1.2)$ & $50.4^{\mathrm{d}}(7.8)$ & $3.8^{\mathrm{d}}(0.8)$ \\
\hline \multicolumn{7}{|l|}{ Within current smokers } \\
\hline Cigarettes/day ${ }^{\mathrm{e}}$ & $17.4^{\mathrm{d}}(2.3)$ & $11.7^{\mathrm{d}}(1.5)$ & $7.6^{\mathrm{d}}(3.3)$ & $21.3^{\mathrm{d}}(1.8)$ & $3.0(8.7)$ & $5.7^{\mathrm{d}}(1.2)$ \\
\hline Not smoked last $24 \mathrm{hrs}^{\mathrm{f}}$ & $-9.8^{\mathrm{d}}(4.1)$ & $-5.6^{\mathrm{d}}(2.7)$ & $-4.0(6.0)$ & $-14.7^{\mathrm{d}}(3.2)$ & $-2.0(15.6)$ & $1.3(2.2)$ \\
\hline Packyears $^{\mathrm{g}}$ & $6.3^{\mathrm{d}}(0.9)$ & $4.3^{\mathrm{d}}(0.6)$ & $3.8^{\mathrm{d}}(1.3)$ & $7.7^{\mathrm{d}}(0.7)$ & $-2.8(3.4)$ & $1.7^{\mathrm{d}}(0.5)$ \\
\hline \multicolumn{7}{|l|}{ Women } \\
\hline \multicolumn{7}{|l|}{ Smoking status ${ }^{\mathrm{c}}$} \\
\hline Never smokers & Reference & & & & & \\
\hline \multicolumn{7}{|l|}{ Former smokers } \\
\hline$\leqslant 1$ year since quitting & $4.1^{\mathrm{d}}(2.0)$ & $9.0^{\mathrm{d}}(2.0)$ & $8.1^{\mathrm{d}}(3.4)$ & $1.7(2.1)$ & $39.3^{\mathrm{d}}(17.2)$ & $2.2(1.3)$ \\
\hline $1-2$ years since quitting & $0.3(3.2)$ & $4.6(3.1)$ & $4.3(5.3)$ & $-2.8(3.3)$ & $2.3(27.3)$ & $0.7(2.1)$ \\
\hline $2-5$ years since quitting & $3.6(2.0)$ & $6.3^{\mathrm{d}}(1.9)$ & $-4.2(3.3)$ & $2.8(2.1)$ & $-5.3(17.1)$ & $1.1(1.3)$ \\
\hline$>5$ years since quitting & $-1.1(0.9)$ & $-1.0(0.9)$ & $3.1^{\mathrm{d}}(1.5)$ & $0.6(0.9)$ & $1.3(7.5)$ & $0.6(0.6)$ \\
\hline Current smokers & $19.2^{\mathrm{d}}(0.8)$ & $18.5^{\mathrm{d}}(0.8)$ & $12.2^{\mathrm{d}}(1.4)$ & $21.5^{\mathrm{d}}(0.9)$ & $43.1^{\mathrm{d}}(7.1)$ & $1.7^{\mathrm{d}}(0.5)$ \\
\hline \multicolumn{7}{|l|}{ Within current smokers } \\
\hline Cigarettes/day ${ }^{\mathrm{e}}$ & $20.9^{\mathrm{d}}(1.5)$ & $15.6^{\mathrm{d}}(1.2)$ & $10.0^{\mathrm{d}}(2.6)$ & $25.4^{\mathrm{d}}(1.4)$ & $-1.9(10.7)$ & $3.6^{\mathrm{d}}(1.0)$ \\
\hline Not smoked last $24 \mathrm{hrs}^{\mathrm{f}}$ & $-7.1^{\mathrm{d}}(2.4)$ & $-8.5^{\mathrm{d}}(2.0)$ & $-9.8^{\mathrm{d}}(4.2)$ & $-7.2^{\mathrm{d}}(2.3)$ & $-20.5(17.4)$ & $-1.1(1.6)$ \\
\hline Packyears ${ }^{\mathrm{g}}$ & $7.6^{\mathrm{d}}(0.6)$ & $5.6^{\mathrm{d}}(0.5)$ & $4.8^{\mathrm{d}}(1.0)$ & $8.5^{\mathrm{d}}(0.6)$ & $0.8(4.1)$ & $1.4^{\mathrm{d}}(0.4)$ \\
\hline
\end{tabular}

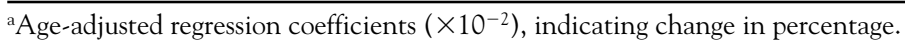

bSE: standard error.

cModel includes smoking status and age.

${ }^{\mathrm{d}} \mathrm{p}$-value $<0.05$.

'Model includes daily number of cigarettes and age; regression coefficients indicate change per 20 cigarettes/day.

${ }^{\mathrm{f}}$ Model includes smoking 24 hours prior to drawing the bloodsample (yes; no), daily number of cigarettes and age.

gModel includes packyears and age; regression coefficients indicate change per 10 packyears.

of the number of cigarettes smoked on erythrocyte count across gender, i.e. depressed levels in smoking men were seen with a negative effect of dose, whereas women had depressed levels in current smokers with a positive effect of dose.

Lymphocytes and neutrophils were the cell types most strongly associated with number of cigarettes per day and packyears, which is consistent with findings in previous studies $(9,16)$. Despite the fact that filter tips reduce tar and nicotine (30), we could not demonstrate a difference between the effects of daily number of filter and non-filter cigarettes on the white blood cells and platelets. Therefore, the substances present in the filter are possibly not responsible for the changes in the hematologic characteristics. The mechanism by which cigarette smoking induces changes in leukocyte and platelet counts is unclear. A persistent positive association between smoking and white blood cell and platelet counts may well reflect an acute or chronic inflammatory response induced by particulates of cigarette smoke $(6,11,13,17)$. Also glycoprotein from to- bacco leaf may stimulate lymphocyte proliferation and differentiation, possibly by interacting with a specific membrane component (25).

Counts of leukocyte subtypes have been associated with several diseases and even some quantitative relations between white blood cells and diseases have been reported. A decrease in leukocyte count of $1000 / \mathrm{mm}^{3}$ (9-25\% increase) has been related to a decrease of $14 \%$ in the risk for cardiovascular heart disease death (1). And an increase of the leukocyte count of $10 \%$ has been related to $6.3 \%$ increase in chronic cough, $6.6 \%$ increase in wheezing and $8.9 \%$ increase in chronic bronchitis (8). Furthermore, each increase in monocytes of $100 / \mathrm{mm}^{3}(13-50 \%$ increase) has been associated with an increase of $15 \%$ in the risk for cardiovascular heart disease (29). These changes were of a magnitude similar to the associations we found with smoking. Substances, released by leukocytes and platelets, could be pathogenic in cancer, cardiovascular and pulmonary diseases $(1-3,7,9-10,29,31-34)$. 
$1 \mathrm{~A}$

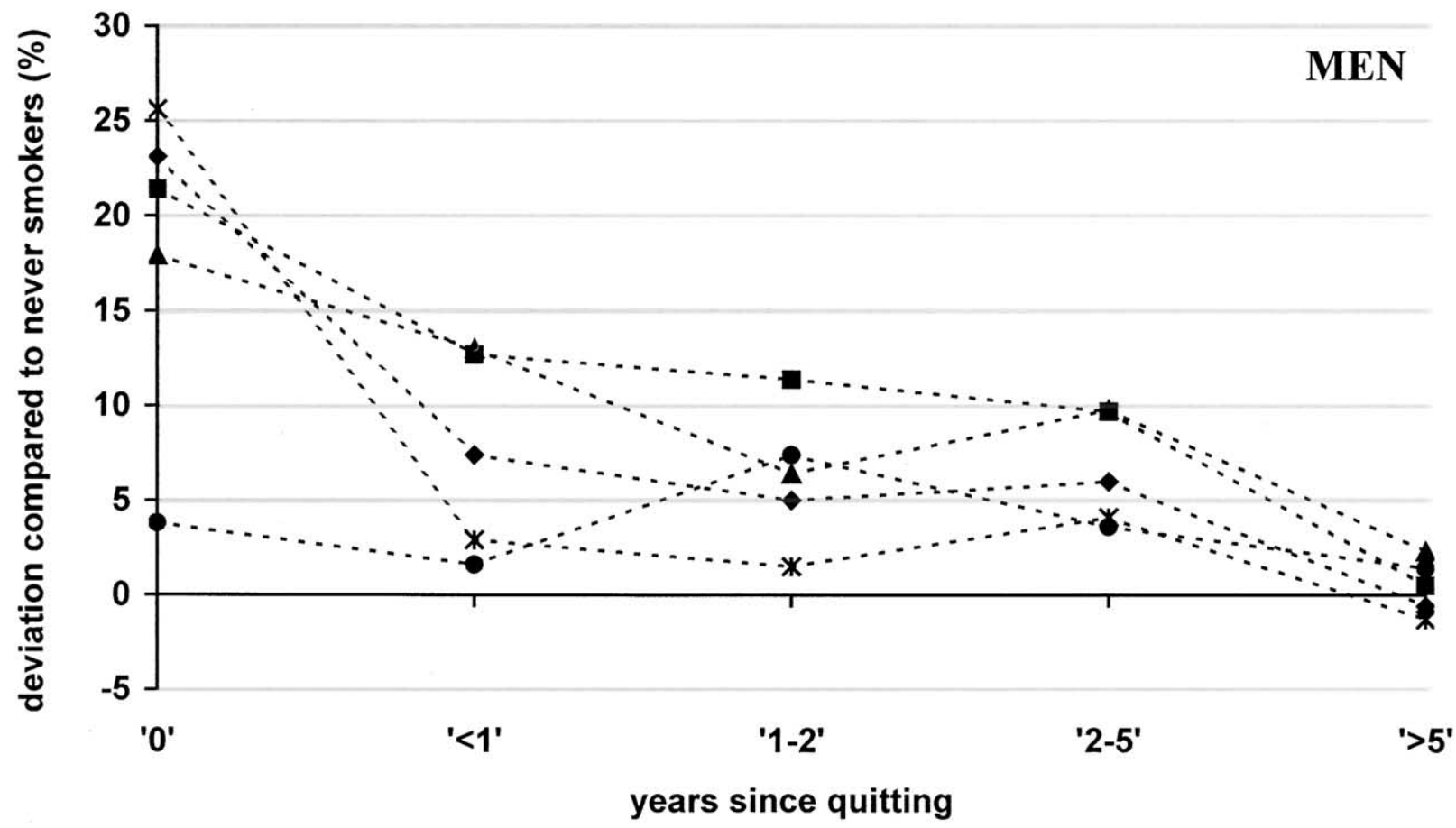

$1 \mathrm{~B}$

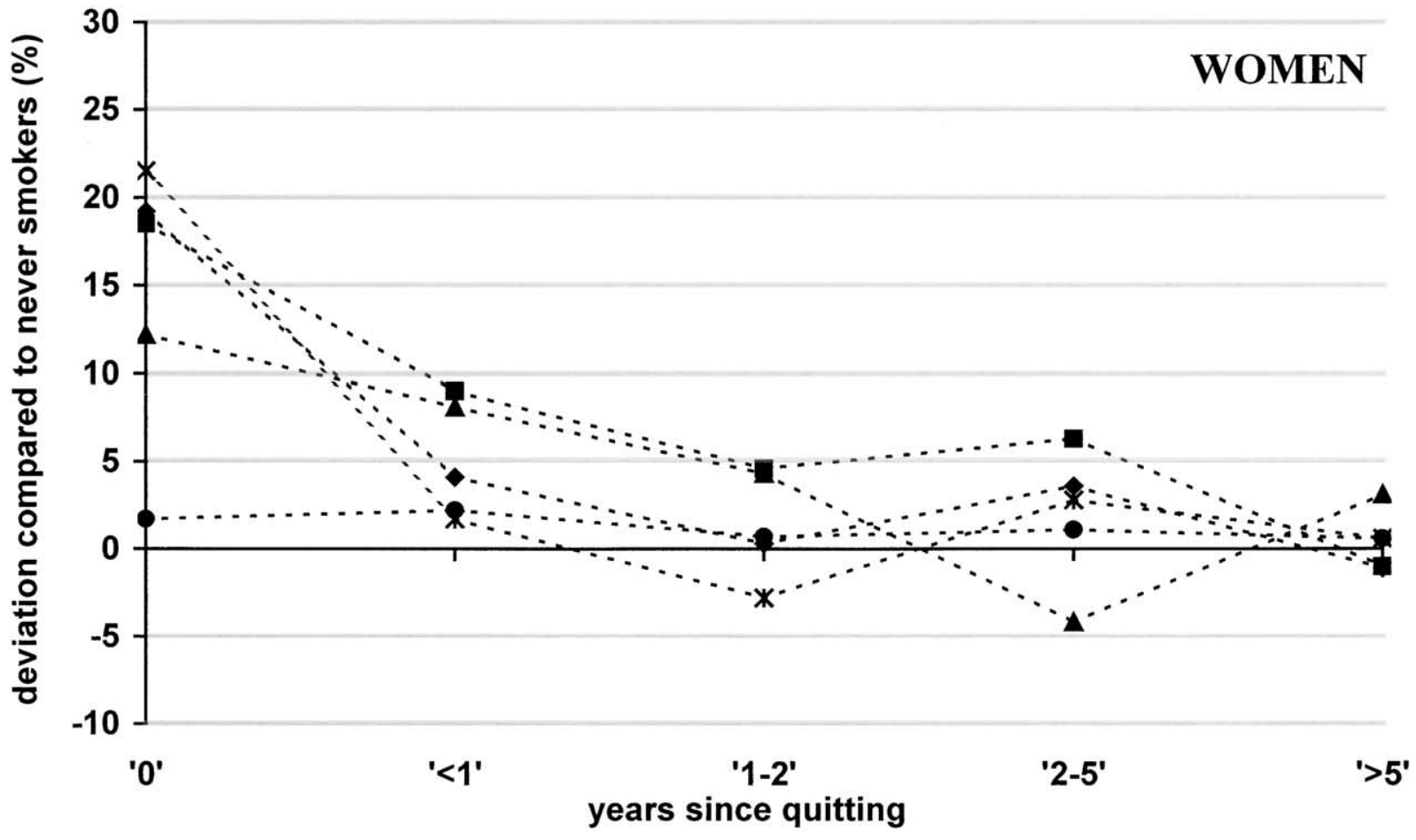

FIGURE 1. A. Levels of leukocytes and thrombocytes after smoking cessation in men: MORGEN-EPIC, 1995-1997. B. Levels of leukocytes and thrombocytes after smoking cessation in women: MORGEN-EPIC, 1995-1997 and PROSPECT-EPIC, 1995-1996. $\bullet$, WBC; lymphocytes; $\boldsymbol{\Delta}$, monocytes; ${ }^{*}$, neutrophils; $\bullet$, thrombocytes. 
TABLE 5. Percentage differences in hematological characteristics of red blood cells between various (ex)smoking categories and nonsmoking (reference) by gender: Dutch EPIC cohort, 1995-1997

\begin{tabular}{|c|c|c|c|c|c|}
\hline & $\mathrm{RBC}$ & $\mathrm{MCV}$ & $\underline{\text { Hematocrit }}$ & Hemoglobin & $\mathrm{MCH}$ \\
\hline & $\beta^{\mathrm{a}}\left(\mathrm{SE}^{\mathrm{b}}\right)$ & $\beta^{\mathrm{a}}(\mathrm{SE})$ & $\beta^{\mathrm{a}}(\mathrm{SE})$ & $\beta^{\mathrm{a}}(\mathrm{SE})$ & $\beta^{\mathrm{a}}(\mathrm{SE})$ \\
\hline \multicolumn{6}{|l|}{ Men } \\
\hline \multicolumn{6}{|l|}{ Smoking status ${ }^{c}$} \\
\hline Never smokers & Reference & & & & \\
\hline \multicolumn{6}{|l|}{ Former smokers } \\
\hline$\leqslant 1$ year since quitting & $-2.2^{\mathrm{d}}(0.6)$ & $0.9^{d}(0.3)$ & $-1.3^{\mathrm{d}}(0.5)$ & $-1.1^{\mathrm{d}}(0.5)$ & $1.0^{\mathrm{d}}(0.5)$ \\
\hline $1-2$ years since quitting & $-0.1(0.9)$ & $-0.2(0.5)$ & $-0.3(0.7)$ & $-0.4(0.7)$ & $-0.3(0.7)$ \\
\hline $2-5$ years since quitting & $-1.2^{\mathrm{d}}(0.6)$ & $0.4(0.3)$ & $-0.8(0.5)$ & $-0.4(0.5)$ & $0.7(0.5)$ \\
\hline$>5$ years since quitting & $-0.3(0.3)$ & $0.2(0.2)$ & $-0.1(0.3)$ & $-0.1(0.2)$ & $0.1(0.3)$ \\
\hline Current smokers & $-2.3^{\mathrm{d}}(0.3)$ & $2.4^{\mathrm{d}}(0.2)$ & $0.1(0.2)$ & $0.3(0.2)$ & $2.8^{\mathrm{d}}(0.2)$ \\
\hline \multicolumn{6}{|l|}{ Within current smokers } \\
\hline Cigarettes/day ${ }^{\mathrm{e}}$ & $-0.4(0.4)$ & $1.3^{\mathrm{d}}(0.2)$ & $0.9^{\mathrm{d}}(0.3)$ & $1.1^{\mathrm{d}}(0.3)$ & $1.3^{\mathrm{d}}(0.4)$ \\
\hline Not smoked last $24 \mathrm{hrs}^{\mathrm{f}}$ & $1.1(0.6)$ & $-1.4^{\mathrm{d}}(0.4)$ & $-0.4(0.6)$ & $-0.6(0.5)$ & $-2.0^{\mathrm{d}}(0.7)$ \\
\hline Packyears $^{\mathrm{g}}$ & $-0.1(0.1)$ & $0.4^{\mathrm{d}}(0.1)$ & $0.3^{\mathrm{d}}(0.1)$ & $0.4^{\mathrm{d}}(0.1)$ & $0.3(0.2)$ \\
\hline \multicolumn{6}{|l|}{ Women } \\
\hline \multicolumn{6}{|l|}{ Smoking status ${ }^{\mathrm{c}}$} \\
\hline Never smokers & Reference & & & & \\
\hline \multicolumn{6}{|l|}{ Former smokers } \\
\hline$\leqslant 1$ year since quitting & $-2.4^{\mathrm{d}}(0.5)$ & $2.2^{\mathrm{d}}(0.3)$ & $-0.1(0.4)$ & $0.0(0.4)$ & $2.5^{\mathrm{d}}(0.3)$ \\
\hline $1-2$ years since quitting & $-1.6^{\mathrm{d}}(0.7)$ & $1.4^{\mathrm{d}}(0.5)$ & $-0.1(0.7)$ & $0.0(0.7)$ & $1.5^{\mathrm{d}}(0.5)$ \\
\hline $2-5$ years since quitting & $-1.6^{\mathrm{d}}(0.5)$ & $1.9^{\mathrm{d}}(0.3)$ & $0.4(0.4)$ & $0.6(0.4)$ & $2.1^{\mathrm{d}}(0.3)$ \\
\hline$>5$ years since quitting & $-1.1^{\mathrm{d}}(0.2)$ & $0.8^{\mathrm{d}}(0.1)$ & $-0.3(0.2)$ & $-0.2(0.2)$ & $0.9^{\mathrm{d}}(0.2)$ \\
\hline Current smokers & $-1.2^{\mathrm{d}}(0.2)$ & $3.4^{\mathrm{d}}(0.1)$ & $2.3^{\mathrm{d}}(0.2)$ & $2.7^{\mathrm{d}}(0.2)$ & $3.9^{\mathrm{d}}(0.1)$ \\
\hline \multicolumn{6}{|l|}{ Within current smokers } \\
\hline Cigarettes/day ${ }^{\mathrm{e}}$ & $1.1^{\mathrm{d}}(0.3)$ & $2.4^{\mathrm{d}}(0.2)$ & $3.6^{\mathrm{d}}(0.3)$ & $3.7^{\mathrm{d}}(0.3)$ & $2.6^{\mathrm{d}}(0.2)$ \\
\hline Not smoked last $24 \mathrm{hrs}^{\mathrm{f}}$ & $-0.4(0.6)$ & $-0.5(0.3)$ & $-0.9(0.5)$ & $-0.9(0.5)$ & $-0.4(0.4)$ \\
\hline Packyears $^{\mathrm{g}}$ & $0.6^{\mathrm{d}}(0.1)$ & $0.8^{\mathrm{d}}(0.1)$ & $1.4^{\mathrm{d}}(0.1)$ & $1.4^{\mathrm{d}}(0.1)$ & $0.9^{\mathrm{d}}(0.1)$ \\
\hline
\end{tabular}

${ }^{a}$ Age-adjusted regression coefficients $\left(\times 10^{-2}\right)$, indicating change in percentage.

b SE: standard error.

${ }^{\mathrm{c}}$ Model includes smoking status and age.

d $p$-value $<0.05$.

'Model includes daily number of cigarettes, and age; regression coefficients indicate change per 20 cigarettes/day.

${ }^{\mathrm{f}}$ Model includes smoking 24 hours prior to drawing the bloodsample (yes; no), daily number of cigarettes and age.

gModel includes packyears and age; regression coefficients indicate change per 10 packyears.

The overall effects of smoking on characteristics of the red blood cell population were less than on the white blood cell population. The results showed increases in MCV, hematocrit, hemoglobin, and $\mathrm{MCH}$ with daily number of cigarettes and packyears. An increased hematocrit may reduce the coronary blood flow and increase adhesion of platelets to the aortic subendothelium, which may contribute to the early formation of atherosclerosis (35) and thromboembolic disease (17). Some possible mechanisms are reported by which cigarette smoking could cause such changes in the red blood cells. Carbon monoxide, one of the chemicals identified in tobacco smoke, may induce hypoxia (17).

The elevated hemoglobin and hematocrit could be a compensatory response to this chronic carbon monoxideinduced hypoxia $(17,21,26)$. However, usually the body responds to hypoxia by increasing the number of erythrocytes too. Cyanide, another chemical in cigarette smoke, which is an antagonist in the process of nucleoprotein synthesis, may prevent this. However, there is no impairment of hemoglobin synthesis. Therefore, the overall effect would be little change in erythrocyte count and an increase in $\mathrm{MCV}$, hematocrit, hemoglobin, and $\mathrm{MCH}$. The fact that only in women the red blood cell count is increased with smoking intensity may be explained by a possible difference in sensitivity to carbon monoxide and cyanide between men and women.

From previous studies a decrease of leukocytes after smoking cessation has been reported $(9-11,14,16)$. Although the effect of years since quitting is biased by duration of smoking $(\mathrm{r}=-0.4)$, in view of public health, it is informative to know how long the effects of past smoking endures. The cross-sectional relations we observed suggest, that longitudinally favourable changes in levels in neutrophils may take place within the first year and in eosinophils 

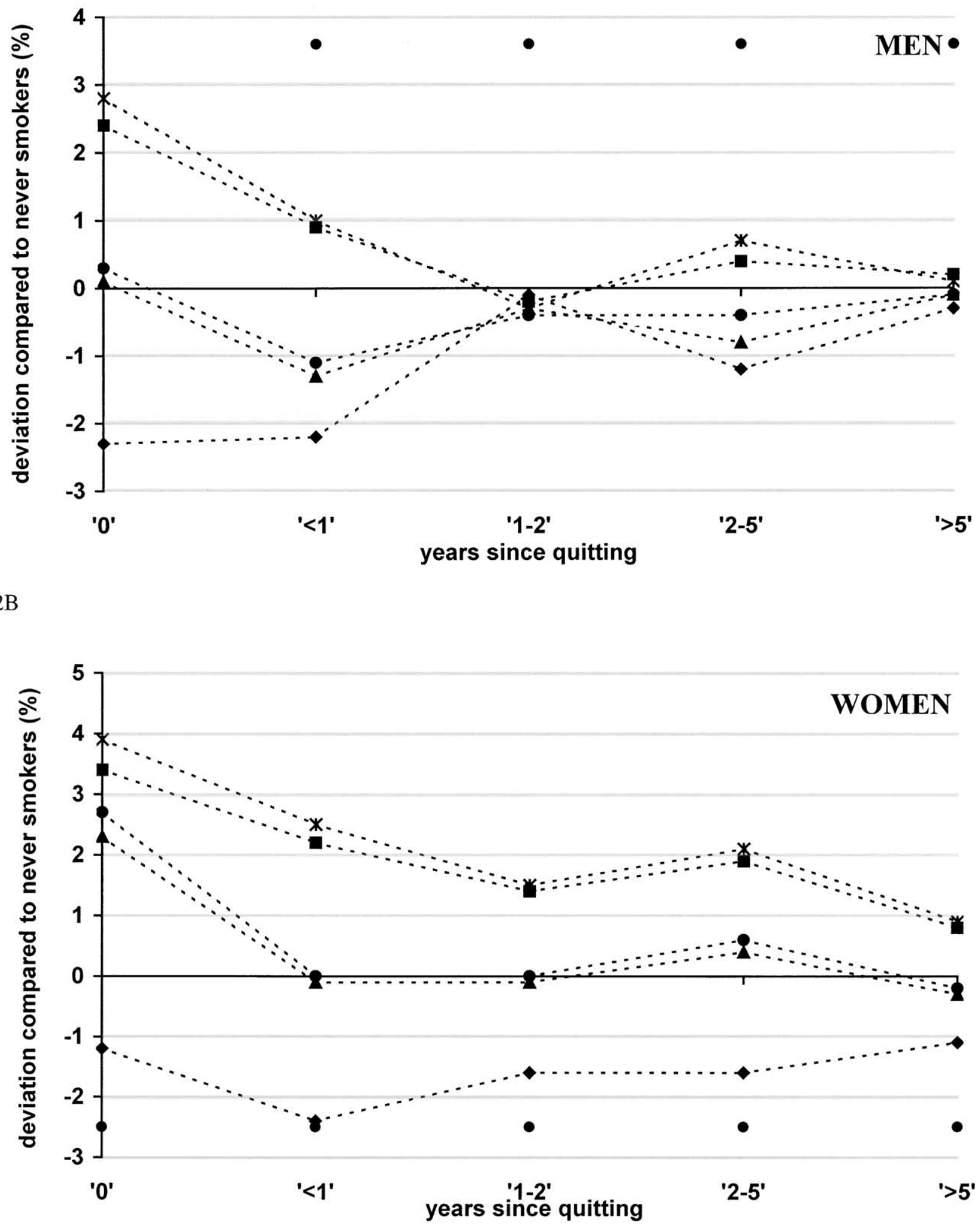

FIGURE 2. A. Levels of erythrocytes after smoking cessation in men: MORGEN-EPIC, 1995-1997. B. Levels in erythrocytes after smoking cessation in women: MORGEN-EPIC, 1995-1997 and PROSPECT-EPIC, 1995-1996. •, RBC; $\mathbf{\square}, \mathrm{MCV} ; \boldsymbol{\nabla}$, hematocrit; •, hemoglobin; *, MCH. 
within two years following quitting, but that the decline to normal levels of lymphocytes and monocytes may be more gradual and may take up to five years.

Our findings suggest that in women, the disappearance of abnormalities in hematocrit and hemoglobin levels may also occur within one year after smoking cessation, whereas the erythrocyte count, $\mathrm{MCV}$, and $\mathrm{MCH}$ may take at least five years to return to normal values. On the other hand, our results point to the possibility that in men, all characteristics of the red blood cell population may return to normal levels within two years. Overall, our results suggest that the return to about normal counts of leukocytes, platelets and erythrocytes may occur within two years after smoking cessation. Our results may also be consistent with a clear improvement in most hematologic characteristics following a period of not smoking for as short as 24 hours. A biological plausible explanation may be related to the same factors that induce normal diurnal variations in hematologic characteristics (36).

The results of our study are consistent with profound effects of smoking on most hematological characteristics in both men and women. Findings suggest that, despite the possibility of a relatively fast recovery during the first two years after quitting, some long-term abnormalities may last up to five years following smoking cessation.

The authors wish to thank all the lab technicians, who have participated in the study over the years, and the epidemiologist and field workers in the study centers for data-collection. Further, we wish to acknowledge the technical assistance of H.P.M. Jansen and W. Harkema, the clinical field product managers of the Coulter Electronics, The Netherlands. This study was in part made possible by financial support received from the Europe against Cancer Program of the Commission of the European Communities in relation to the European Prospective Investigation into Cancer and $\mathrm{Nu}$ trition. The MORGEN study was financially supported by the Ministry of Public Health, Welfare, and Sports of the Netherlands and the National Institute of Public Health and the Environment.

\section{REFERENCES}

1. Grimm RH, Neaton JD, Ludwig W. Prognostic importance of the white blood cell count for coronary, cancer and all-cause mortality. JAMA. 1985;254(14):1932-1937.

2. Targher G, Seidell JC, Tonoli M, Muggeo M, De Sandre G, Cigolini $\mathrm{M}$. The white blood cell count: Its relationship to plasma insulin and other cardiovascular risk factors in healthy male individuals. J Int Med. 1996;239:435-441.

3. Sweetnam PM, Thomas HF, Yarnell JWG, Baker IA, Elwood PC. Total and differential leukocyte counts as predictors of ischemic heart disease: The Caerphilly and Speedwell studies. Am J Epidemiol. 1997;145(5):416-421.

4. Friedman GD, Tekawa I, Grimm RH, Manolio T, Shannon SG, Sidney S. The leukocyte count: Correlates and relationship to coronary risk factors: The CARDIA study. Int J Epidemiol. 1990;19(4):889-893.

5. Friedman GD, Fireman BH. The leukocyte count and cancer mortality. Am J Epidemiol. 1991;133(4):376-380.

6. Hansen LK, Grimm RH, Neaton JD. The relationship of white blood cell count to other cardiovascular risk factors. Int J Epidemiol. 1990; 19(4):881-888.

7. Sparrow D, Glynn RJ, Cohen M, Weiss ST. The relationship of peripheral leukocyte count and cigarette smoking to pulmonary function among adult males. Chest. 1984;86:383-386.

8. Schwartz J, Weiss ST. Peripheral blood leukocyte count and respiratory symptoms. Ann Epidemiol. 1993;3:57-63.

9. Freedman DS, Flanders WD, Barboriak JJ, Malarcher AM, Gates L. Cigarette smoking and leukocyte subpopulations in men. Ann Epidemiol. 1996;6(4):299-306.

10. Sunyer J, Muñoz A, Peng Y, Margolick J, Chmiel JS, Oishi J, et al. Longitudinal relation between smoking and white blood cells. Am J Epidemiol. 1996;144(8):734-741.

11. Yarnell JWG, Sweetnam PM, Rogers S, Elwood PC, Bainton D, Baker IA, et al. Some long term effects of smoking on the haemostatic system: A report from the Caerphilly and Speedwell collaborative surveys. J Clin Pathol. 1987;40:909-913.

12. Nieto FJ, Szklo M, Folsom AR, Rock R, Mercuri M. Leukocyte count correlates in middle-aged adults: The Atherosclerosis Risk In Communities (ARIC) study. Am J Epidemiol. 1992; 136(5):525-537.

13. Schwartz J, Weiss ST. Host and environmental factors influencing the peripheral blood leukocyte count. Am J Epidemiol. 1991;134:1402-409.

14. Petitti DB, Kipp H. The Leukocyte count: Associations with intensity of smoking and persistence of effect after quitting. Am J Epidemiol. 1986;123(1):89-95.

15. Freedman DS, Joesoef MR, Barboriak JJ, Stallone DD, Byers T. Correlates of leukocyte counts in men. Ann Epidemiol. 1996;6:74-82.

16. Schwartz J, Weiss ST. Cigarette smoking and peripheral blood leukocyte differentials. Ann Epidemiol. 1994;4:236-242.

17. Helman N, Rubenstein LS. The effects of age, sex, and smoking on erythrocytes and leukocytes. Am J Clin Path. 1975;63:35-44.

18. Tell GS, Grimm RH, Vellar OD, Theodorsen L. The relationship of white cell count, platelet count, and hematocrit to cigarette smoking in adolescents: The Oslo Youth study. Circulation. 1985;72(5):971-974.

19. Green MS, Peled I, Najenson T. Gender differences in platelet count and its association with cigarette smoking in a large cohort in Israel. J Clin Epidemiol. 1992;45(1):77-84.

20. Whitehead TP, Robinson D, Allaway SL, Hale AC. The effects of cigarette smoking and alcohol consumption on blood haemoglobin, erythrocytes and leukocytes: A dose related study on male subjects. Clin Lab Haem. 1995;17:131-138.

21. McKarns SC, Smith CJ, Payne M, Doolittle DJ. Blood parameters associated with atherogenic and thrombogenic risk in smokers and nonsmokers with similar life-styles. Mod Path. 1995;8:434-440.

22. Riboli E. Nutrition and cancer: Background and rationale of the European prospective investigation into cancer and nutrition. Ann Oncol. 1993;3:783-791.

23. Ocké MC, Bueno-de-Mesquita HB, Goddijn HE, Jansen A, Pols, MA, van Staveren WA, et al. The Dutch EPIC food frequency questionnaire. I. Description of the questionnaire, and relative validity and reproducibility for food groups. Int J Epidemiol. 1997;26(1):S37-S48.

24. Goldbourt U, Medalie JH. Characteristics of smokers, non-smokers and ex-smokers among 10,000 adult males in Israel. Am J Epidemiol. 1977;105:75-86.

25. Francus T, Klein RF, Staino-Coico L, Becker CG, Siskind GW. Effects of tobacco glycoprotein (TGP) on the immune system. II. TGP stimulates the proliferation of human $\mathrm{t}$ cells and the differentiation of human b cells into Ig secreting cells. J Immunol. 1988;140:1823-1829.

26. Hoffbrand AV, Pettit JE. Essential Haematology. Oxford, UK: Blackwell Science; 1993.

27. Chalmers DM, Levi AJ, Chanarin I, Meade TW. Mean cell volume in a working population: The effects of age, smoking, alcohol and oral contraceptive. Br J Haematol. 1979;43(3):631-636. 
28. Cruickshank JM, Alexander MK. The effect of age, sex, parity, haemoglobin level, and oral contraceptive preparations on the normal leucocyte count. Br J Haematol. 1970;18:541-550.

29. Olivares R, Ducimetière $\mathrm{P}$, Claude JR. Monocyte count: A risk factor or coronary heart disease? Am J Epidemiol. 1993;137(1):49-53.

30. Hoffmann D, Hoffmann I. The changing cigarette, 1950-1995. J Toxicol Environ Health. 1997;50(4):307-364.

31. Ernst E, Hammerschmidt DE, Bagge U, Matrai A, Dormandy JA. Leukocyte and the risk of ischemic heart diseases. JAMA. 1987; 257(17): 2318-2324.

32. Schwartz JD, Shamamian P, Marcus SG, Monea S, Whiting D, Patel $\mathrm{S}$, et al. Activation of endothelial cell pro-matrix metalloproteinase-2 by neutrophil-derived serine proteinases. Proceedings of the American Association for Cancer Research. 1998;39:558.

33. Hammer JH, Vangsgaard K, Brünner N, Nielsen HJ. VEGF may be stored as presynthesized molecule in intracellular granules of leukocytes or platelets. Proceedings of the American Association for Cancer Research. 1998;39:1027.

34. Rothenberg ME. Eosinophilia. N Eng J Med. 1998;338:1592-1600.

35. Campbell MJ, Elwood PC, Mackean J, Waters WE. Mortality, haemoglobin level and hematocrit in women. J Chron Dis. 1985;38:881-889.

36. Pocock SJ, Ashby D, Shaper AG, Walker M, Broughton PMG. Diurnal variations in serum biochemical and hematological measurements. J Clin Pathol. 1989;42:172-179. 